\title{
Isomerization of $\beta$-carotene by titanium tetrachloride catalyst
}

\author{
V RAJENDRAN ${ }^{1, *}$ and $\mathrm{B} \mathrm{H} \mathrm{CHEN}^{2}$ \\ ${ }^{1}$ Department of Chemistry, Pachaiyappa's College for Men, Kanchipuram \\ ${ }^{2}$ Department of Nutrition and Food Sciences, Fu Jen University, Taipei, Taiwan 242 \\ e-mail: vrshobana01@yahoo.co.in
}

MS received 22 February 2007; revised 4 May 2007

\begin{abstract}
Isomerization of all-trans- $\beta$-carotene occurs during shaking with $0.5 \%$ of titanium tetrachloride catalyst in methylene chloride at room temperature. In the present study we compared two types of columns $\mathrm{C} 18$ and $\mathrm{C} 30$ and various solvent systems for the separation of $\beta$-carotene and its cis isomers by high performance liquid chromatography (HPLC). Results showed that $\beta$-carotene isomers were resolved by employing a C30 column with a mobile phase of methanol (100\%) (A) and methylene chloride $(100 \%)(B)$ under a gradient elution condition. A total of eleven cis isomers and one all-trans- $\beta$-carotene isomer were resolved within $50 \mathrm{~min}$ at a flow rate of $1 \mathrm{ml} / \mathrm{min}$ and detection wave-length of $470 \mathrm{~nm}$.
\end{abstract}

Keywords. $\beta$-Carotene; liquid chromatography; isomerization; titanium tetrachloride catalyst.

\section{Introduction}

$\beta$-carotene is an important carotenoid compound that is widely distributed in fruits and vegetables. It has received considerable attention in the past decade because of their beneficial effects on human health. Epidemiological studies have shown that the consumption of fruits and vegetables high in carotenoid content can elevate all-trans- $\beta$-carotene levels in the blood, which in turn can protective against some fatal diseases such as skin and stomach cancer. ${ }^{1,2}$ In addition to being a vitamin $\mathrm{A}$ precursor, all-trans- $\beta$ carotene ( $\beta$-carotene, $C_{2 h}$ symmetry) is also effective antioxidant because of the presence of a long chain of conjugated carbon-carbon double bonds. ${ }^{3,4}$

Most $\beta$-carotene is naturally present in the trans form; however, there are still significant amounts of cis forms of $\beta$-carotene in foods. The cis isomers of $\beta$-carotene in foods may be identified by the methods such as extraction, chromatography etc. It has been reported that the chlorinated solvents can promote isomerization of trans conjugated polyenes such as $\beta$-carotene during extraction. ${ }^{5}$ Also, the isomerization of $\beta$-carotene was found to be relatively higher in non-polar solvents than that of polar solvents. ${ }^{6}$ Because of the increased awarness of the involvement of trans/cis isomerization of carotenoids in many

*For correspondence biochemical and biological processes, numerous methods of isolation and detection of trans/cis isomers, ${ }^{7,9}$ as well as their preparation, have been developed. The methods leading to formation of mixtures of cis and trans isomers include refluxing in organic solvents, melting of crystals, contact for prolonged period with certain active surfaces, treatment with acids, and irradiation of solution with or without iodine catalyst. ${ }^{10,11}$

During food processing, $\beta$-carotene may undergo degradation and isomerization simultaneously and the formation of $c i s$ isomers of $\beta$-carotene may reduce its color intensity and biological activity. Some recent studies suggested that several cis isomers of $\beta$ carotene such as 9 -cis and 13-cis $\beta$-carotene are present in human serum. ${ }^{12}$

Traditionally, the separation of carotenoids in food samples is often carried out by HPLC with a C18 column. However, most HPLC methods employing a C18 column failed to resolve all-trans carotenoids and its cis isomers. To remedy this problem the application of a C30 column for separation of all-trans carotenoids and its cis isomers has been developed. ${ }^{13,14}$ Now for the first time we report that trans/cis isomerization can also be achieved by using $0.5 \%(\mathrm{v} / \mathrm{v})$ titanium tetrachloride catalyst in methylene chloride with mild shaking at room temperature. The peaks due to isomerized $\beta$-carotene are separated by HPLC. Figure 1 shows structures of the predominant geometrical isomers of $\beta$-carotene. 
<smiles>CC1=C(/C=C(C)/C=C/C=C/C=C(C)/C=C/C=C(C)/C=C/C=C/C=C(\C)C2=C(C)CCCC2(C)C)C(C)(C)CCC1</smiles>

All-trans $\beta$-carotene
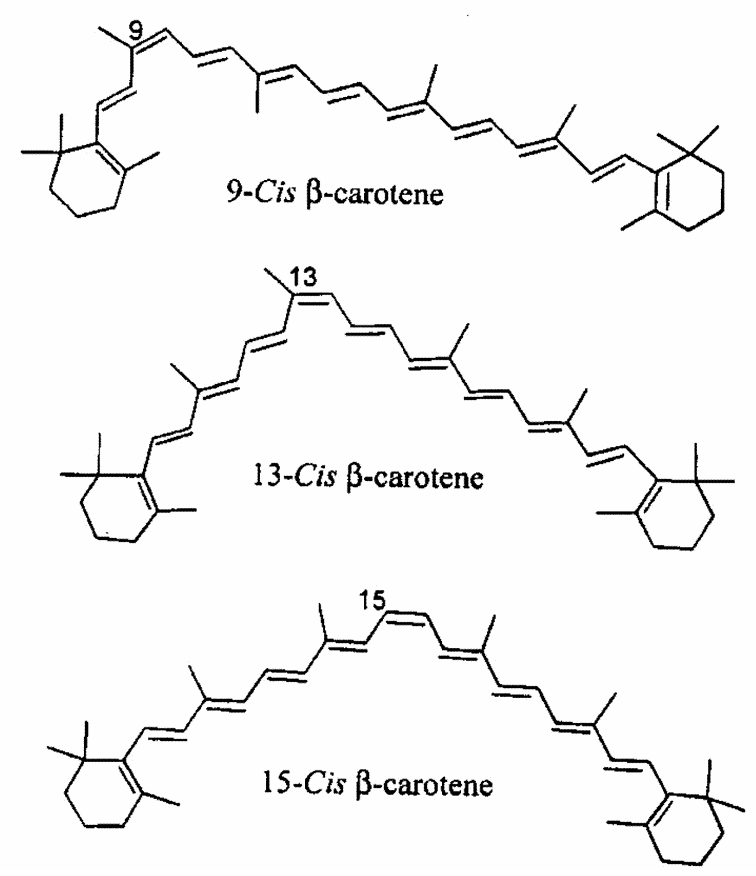

Figure 1. Structures of major isomers of $\beta$-carotene.

\section{Experimental}

\subsection{Materials}

All-trans- $\beta$-carotene standard was obtained from Sigma Co. (St. Louis, MO, USA). The HPLC-grade solvents, including methanol, methylene chloride, acetone, acetonitrile, titanium tetrachloride and hexane were from Mallinckrodt Co. (Paris, KY, USA). Deionized water was prepared using Milli-Q water purification system (Millipore Co., Bedford, MA, USA). A C18 column (Hypersil 5-19626: $150 \times$ $4.6 \mathrm{~mm}$ i.d., $5 \mu \mathrm{m}$ particle size) was purchased from Thermo Electron Co. (Bellefonte, PA, USA) and a C30 column (YMCRP 30: $250 \times 4.6 \mathrm{~mm}$ i.d., $5 \mu \mathrm{m}$ particle size) was from Waters Corp. (Milford, MA, USA).

\subsection{Instrumentation}

The HPLC system is composed of a Phenomenex DG-440 degasser (Phenomenex Co., Torrance, CA, USA), a Rheodyne model 7161 injector (Rheodyne Co., CA, USA), an Agilent model 1100 UV-Vis de- tector, a Jasco MD-915 photodiode-array detector (Tokyo, Japan), and a Borwin computer software system. The sonicator (model 2210R-DTH) was from Branson Co., (Danbury, CT, USA). The freezedryer (model FD-24) was from Chin-Ming Co., (Taipei, Taiwan).

\subsection{Titanium tetrachloride catalysed isomerization of all-trans- $\beta$-carotene}

Five numbers of $10 \mathrm{ml}$ vials were taken, each vial containing $2 \mathrm{ml}$ of $100 \mu \mathrm{g} / \mathrm{ml}(100 \mathrm{ppm})$ of alltrans- $\beta$-carotene standard in methylene chloride. The methylene chloride was removed by passing nitrogen gas. After drying, the standard residue was redissolved in $2 \mathrm{ml}$ of $0.5 \%(\mathrm{v} / \mathrm{v})$ titanium tetrachloride containing methylene chloride solution. All the vials were subjected to mild shaking at $200 \mathrm{rpm}$ for $1,3,5,7$ and $9 \mathrm{~h}$ at room temperature. After shaking the standards were then dried under a stream of nitrogen. The residue were finally dissolved in $100 \mu \mathrm{l}$ sample solvent of methanol : methylene chloride $(55: 45, \mathrm{v} / \mathrm{v})$ and filtered through a $0.2 \mu \mathrm{m}$ membrane filter for the HPLC analysis. The sample which underwent five hours shaking yielded high number of cis isomers of $\beta$-carotene than the others. From the HPLC chromatogram the cis-trans isomers were tentatively identified based on spectral characteristics and Q-ratios [i.e., ratio of absorbances at the near-UV maxima and main absorbance maxima], reported in the literature ${ }^{15-20}$ (tables 1 and 2).

\subsection{HPLC analysis of $\beta$-carotene isomers}

Various binary and ternary solvent systems were tried for the separation efficiency of $\beta$-carotene isomers. Two different binary solvent systems in different proportions, one system containing methanolmethylene chloride $(99: 1,97: 3$, and $95: 5, \mathrm{v} / \mathrm{v})$ were used in isocratic condition and another system containing methanol-isopropanol $(95: 5, \mathrm{v} / \mathrm{v})$ (A) and methylene chloride (100\%) (B) was used in the gradient condition. Likewise, two ternary solvent systems in different proportions, one system containing $n$-butanol/acetonitrile/methylene chloride $(30: 70: 10, \mathrm{v} / \mathrm{v} / \mathrm{v})$ and another system containing isopropanol/acetonitrile/methylene chloride (25: $70: 5,25: 70: 10$ and $25: 70: 20, \mathrm{v} / \mathrm{v} / \mathrm{v})$ were used. The solvent strength of each mobile phase was carefully controlled by calculating the polarity index. In addition, the separation efficiency in different 
Table 1. Retention time, retention factor $\left(k^{\prime}\right)$, separation factor $(\alpha)$, and Q-ratio of isomerized $\beta$-carotene by titanium tetrachloride catalyst.

\begin{tabular}{|c|c|c|c|c|c|c|}
\hline Peak no. & Compound & Retention time (min) & $k^{\prime a}$ & $\alpha^{\mathrm{b}}$ & Q-ratio found & Q-ratio reported \\
\hline 1 & Cis- $\beta$-carotene & $19 \cdot 17$ & $4 \cdot 36$ & $1 \cdot 19$ & - & - \\
\hline 2 & Cis- $\beta$-carotene & $22 \cdot 20$ & $5 \cdot 20$ & $1 \cdot 11$ & - & - \\
\hline 3 & Cis- $\beta$-carotene & $24 \cdot 24$ & $5 \cdot 77$ & 1.07 & - & - \\
\hline 4 & 15 or $15^{\prime}-c i s-\beta$-carotene & 25.64 & $6 \cdot 16$ & 1.04 & 0.44 & $0.43^{\mathrm{d}}$ \\
\hline 5 & 9 or $9^{\prime}-c i s-\beta$-carotene & $26 \cdot 61$ & $6 \cdot 43$ & 1.08 & $0 \cdot 13$ & $0.09^{\mathrm{e}}$ \\
\hline 6 & 13 or $13^{\prime}$-cis- $\beta$-carotene & $28 \cdot 56$ & 6.97 & $1 \cdot 12$ & $0 \cdot 36$ & $0 \cdot 35^{\mathrm{f}}$ \\
\hline 7 & All-trans- $\beta$-carotene & $31 \cdot 51$ & $7 \cdot 81$ & 1.04 & 0.08 & $0 \cdot 08^{\mathrm{g}}$ \\
\hline 8 & 13 or $13^{\prime}$-cis- $\beta$-carotene & 32.72 & $8 \cdot 14$ & 1.08 & $0 \cdot 35$ & $0 \cdot 35^{\mathrm{f}}$ \\
\hline 9 & Cis- $\beta$-carotene & $35 \cdot 12$ & $8 \cdot 81$ & $1 \cdot 04$ & - & - \\
\hline 10 & 15 or $15^{\prime}$-cis- $\beta$-carotene & $36 \cdot 28$ & $9 \cdot 13$ & $1 \cdot 03$ & 0.43 & $0.43^{\mathrm{d}}$ \\
\hline 11 & 9 or $9^{\prime}$-cis- $\beta$-carotene & $37 \cdot 12$ & $9 \cdot 37$ & 1.04 & $0 \cdot 12$ & $0.09^{\mathrm{e}}$ \\
\hline 12 & Cis- $\beta$-carotene & 38.48 & $9 \cdot 75$ & $1 \cdot 03$ & - & - \\
\hline
\end{tabular}

${ }^{\mathrm{a}} k^{\prime}$ (Retention factor or capacity factor) $=\left(t_{R 1}-t_{0}\right) / t_{0}$, where $t_{R}$ denotes retention time of sample components and $\mathrm{t}_{0}$ denotes retention time of sample solvent

${ }^{\mathrm{b}} \alpha$ (Selectivity factor or separation factor $)=\left(t_{R 2}-t_{0}\right) /\left(t_{R 1}-t_{0}\right)$

${ }^{c}-$, Data not available

${ }^{\mathrm{d}}$ A gradient mobile phase of 1-butanol-acetonitrile $(30: 70, \mathrm{v} / \mathrm{v})$ and methylene chloride (from $99: 1, \mathrm{v} / \mathrm{v}$ to $90: 10$, $\mathrm{v} / \mathrm{v}$ ) was used by Lin and $\mathrm{Chen}^{15}$

${ }^{\mathrm{e}} \mathrm{A}$ mobile phase of methanol-methyl-tert-butyl ether (MTBE) $(75: 25, \mathrm{v} / \mathrm{v})$ was used by Bohm et $a l^{16}$

${ }_{\mathrm{f}}^{\mathrm{A}}$ mobile phase of acetone-hexane $(3: 97, \mathrm{v} / \mathrm{v})$ was used by Tsukida et al $^{17}$

${ }^{8}$ A mobile phase of methanol-methylene chloride-isopropanol $(89: 1: 10, \mathrm{v} / \mathrm{v} / \mathrm{v})$ was used by Tai and $\mathrm{Chen}^{18}$

Table 2. Identification data for all-trans and cis forms of $\beta$-carotene after catalysed by titanium tetrachloride.

\begin{tabular}{clccccccc}
\hline Peak no. & \multicolumn{1}{c}{ Compound } & Retention time $(\mathrm{min})$ & \multicolumn{3}{c}{$\lambda(\mathrm{nm})$ (in-line) } & \multicolumn{3}{c}{$\lambda(\mathrm{nm})$ (reported) } \\
\hline 1 & Cis- $\beta$-carotene & $19 \cdot 17$ & 413 & 433 & 458 & 413 & 437 & $458^{\mathrm{b}}$ \\
2 & Cis- $\beta$-carotene & $22 \cdot 20$ & 417 & 441 & 464 & 417 & 441 & $464^{\mathrm{c}}$ \\
3 & Cis- $\beta$-carotene & $24 \cdot 24$ & 417 & 435 & 465 & 417 & 447 & $471^{\mathrm{c}}$ \\
4 & 15 or 15'-cis- $\beta$-carotene & $25 \cdot 64$ & 419 & 447 & 471 & 421 & 443 & $470^{\mathrm{d}}$ \\
5 & 9 or 9'-cis- $\beta$-carotene & $26 \cdot 61$ & 418 & 447 & 471 & 422 & 447 & $473^{\mathrm{e}}$ \\
6 & 13 or 13'-cis- $\beta$-carotene & $28 \cdot 56$ & 419 & 447 & 471 & 419 & 442 & $465^{\mathrm{f}}$ \\
7 & All-trans- $\beta$-carotene & $31 \cdot 51$ & 429 & 453 & 477 & 426 & 454 & $478^{\mathrm{g}}$ \\
8 & 13 or 13'-cis- $\beta$-carotene & $32 \cdot 72$ & 419 & 447 & 471 & 419 & 442 & $465^{\mathrm{f}}$ \\
9 & Cis- $\beta$-carotene & $35 \cdot 12$ & 417 & 441 & 465 & 417 & 441 & $459^{\mathrm{c}}$ \\
10 & 15 or 15'-cis- $\beta$-carotene & $36 \cdot 28$ & 419 & 447 & 471 & 421 & 443 & $470^{\mathrm{d}}$ \\
11 & 9 or 9'-cis- $\beta$-carotene & $37 \cdot 12$ & 418 & 447 & 471 & 422 & 447 & $473^{\mathrm{e}}$ \\
12 & Cis- $\beta$-carotene & $38 \cdot 48$ & 417 & 441 & 471 & 417 & 441 & $471^{\mathrm{c}}$ \\
\hline
\end{tabular}

${ }^{\mathrm{a}} \mathrm{A}$ gradient mobile phase of methanol (100\%) (A) and methylene chloride (100\%) (B) from (90:10, v/v to $52: 48$, $\mathrm{v} / \mathrm{v}$ ) was used

${ }^{\mathrm{b}} \mathrm{A}$ mobile phase of methanol-methylene chloride $(99: 1, \mathrm{v} / \mathrm{v})$ was used by Chen et $a l^{19}$

${ }^{\mathrm{c}} \mathrm{A}$ mobile phase of methanol-isopropanol $(99: 1, \mathrm{v} / \mathrm{v})$ and methylene chloride (from $100: 0, \mathrm{v} / \mathrm{v}$ to $70: 30$, v/v) was used by Chen $e t a l^{20}$

${ }^{\mathrm{d}} \mathrm{A}$ gradient mobile phase of 1-butanol-acetonitrile $(30: 70, \mathrm{v} / \mathrm{v})$ and methylene chloride (from $99: 1, \mathrm{v} / \mathrm{v}$ to $90: 10$, v/v) was used by Lin and Chen ${ }^{15}$

${ }^{\mathrm{e}} \mathrm{A}$ mobile phase of methanol-methyl-tert-buty lether (MTBE) $(75: 25, \mathrm{v} / \mathrm{v})$ was used by Bohm et $a l^{16}$

${ }^{\mathrm{f}} \mathrm{A}$ mobile phase of acetone-hexane $(3: 97, \mathrm{v} / \mathrm{v})$ was used by Tsukida et $\mathrm{al}^{17}$

${ }^{\mathrm{g}} \mathrm{A}$ mobile phase of methanol-methylene chloride-isopropanol $(89: 1: 10, \mathrm{v} / \mathrm{v} / \mathrm{v})$ was used by Tai and $\mathrm{Chen}^{18}$

sample solvents were also studied. The separation efficiency was evaluated by retention factor $\left(k^{\prime}\right)$ and separation factor $(\alpha)$. After various studies, the most appropriate mobile phase was found to be methanol
$(100 \%)(A)$ and methylene chloride (100\%) (B) with the gradient elution which was explained in the results and discussion section. The most suitable sample solvent was found to be methanol-methylene 
chloride $(55: 45, \mathrm{v} / \mathrm{v})$. The analytical C30 column was used for comparison. The flow rate was $1.0 \mathrm{ml} / \mathrm{min}$ and column temperature was $25^{\circ} \mathrm{C}$ with detection at $470 \mathrm{~nm}$. The injection volume was $20 \mu \mathrm{l}$.

\section{Results and Discussion}

\subsection{HPLC separation of $\beta$-carotene isomers}

Various HPLC conditions have been developed to separate the isomers of $\beta$-carotene using $\mathrm{C} 18$ and C30 columns. It was observed that the C30 column could resolve high numbers of more carotenoid isomers than C18 column, which may be due to a greater hydrophobic interaction between C30 stationary phase with the isomers of $\beta$-carotene. ${ }^{13,14}$ Thus, a C30 column was selected instead of a C18 column for separation of the isomers of $\beta$-carotene.

After various studies, a gradient mobile phase of methanol (100\%) (A) and methylene chloride (100\%) (B) was developed : $90 \% \mathrm{~A}$ and $10 \% \mathrm{~B}$ in the beginning, maintained for $5 \mathrm{~min}$, decreased to $78 \% \mathrm{~A}$ in $15 \mathrm{~min}, 62 \% \mathrm{~A}$ in $30 \mathrm{~min}, 52 \% \mathrm{~A}$ in $40 \mathrm{~min}$, maintained for $10 \mathrm{~min}$ and returned to $100 \% \mathrm{~A}$ in $55 \mathrm{~min}$. A total of $12 \beta$-carotene isomers including one all-trans isomer were resolved within $50 \mathrm{~min}$.

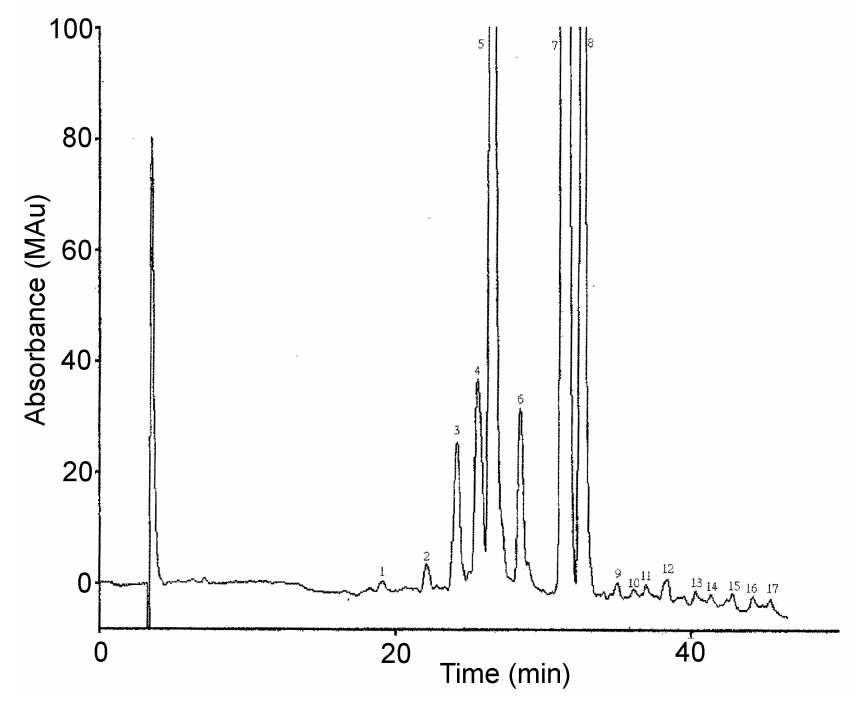

Figure 2. Chromatographic separation of geometrical $\beta$-carotene isomers catalysed by $0.5 \%$ titanium tetrachloride in methylene chloride. Chromatographic conditions described in text. Peaks: 1. cis- $\beta$-carotene; 2. cis- $\beta$ carotene; 3 . cis- $\beta$-carotene; 4 . 15 or $15^{\prime}$-cis- $\beta$-carotene; 5 . 9 or $9^{\prime}-$-cis- $\beta$-carotene; 6.13 or $13^{\prime}$-cis- $\beta$-carotene; 7 . alltrans- $\beta$-carotene; 8.13 or $13^{\prime}$-cis- $\beta$-carotene; 9. cis- $\beta$ carotene; 10.15 or $15^{\prime}$-cis- $\beta$-carotene; 11. 9 or $9^{\prime}-c i s-\beta$ carotene; 12. cis- $\beta$-carotene.
Figure 2 shows the various geometrical isomers of the $\beta$-carotene isomers separated using the YMC C30 column. The separation efficiency was assessed from $k^{\prime}$ and $\alpha$ values, where $k^{\prime}$ denotes retention factor or capacity factor $\left(k^{\prime}=\left(t_{R}-t_{0}\right) / t_{0}\right)$ and $\alpha$ denotes selectivity factor or separation factor $\left(\alpha=\left(t_{R 2}-t_{0}\right) /\right.$ $\left.\left(t_{R 1}-t_{0}\right)\right)$. It has been well established that the $k^{\prime}$ values should be controlled between 0.5 to 20 and the $\alpha$ values should be more than one for good separation to occur $^{21}$ (table 1). In a similar way high degree of shape selectivity by a $5 \mu \mathrm{m}$ polymeric C30 column has been demonstrated for the geometrical isomers of $\alpha$-carotene, lutein, $\beta$-cryptoxanthin, lycopene and zeaxanthin, in addition to $\beta$-carotene. ${ }^{13}$ For the separations of geometrical carotenoid isomers, the stationary phase is reported to be superior to existing reverse phase liquid chromatography (RPLC) columns that are commonly employed for this application. ${ }^{13}$ Appreciable separations of geometrical carotenoid isomers were also been achieved in normalphase liquid chromatography using calcium hydroxide, alumina, silica, and nitrile bonded stationary phases systems. ${ }^{22-29}$

\subsection{Electronic absorption spectra of $\beta$-carotene isomers}

The electronic absorption spectral characteristics obtained for each of the $\beta$-carotene isomers are shown in tables 1 and 2 . All of the spectra were characteristic of $\beta, \beta$-carotenoids with respect to its fine structures ( $\sim 400$ to $500 \mathrm{~nm}){ }^{30,31}$ A total of 12 peaks were resolved. Peak 7 was positively identified as alltrans- $\beta$-carotene with the standard. The other peaks were tentatively identified as cis-isomers of $\beta$ carotene based on spectral characteristics and Qratios as reported in the literature ${ }^{15-20}$ (tables 1 and $2)$. Peaks 4 and 10 were identified as 15 or $15^{\prime}$-cis$\beta$-carotene, while peaks 6 and 8 were identified as 13 or $13^{\prime}$-cis- $\beta$-carotene. Peaks 5 and 11 were identified as 9 or $9^{\prime}-c i s-\beta$-carotene. For these all cis- $\beta$ carotenes the hypsochromic shifts of $6 \mathrm{~nm}$ were detected from their main absorption maxima, relative to that of all-trans- $\beta$-carotene (table 2). In general, a hypsochromic shift of about $5 \mathrm{~nm}$ is observed with the introduction of a cis bond in a carotenoid structure, but the specific magnitude of these shifts depends on the position of the cis bond. Because absorbance in the near UV region generally increases as the position of the cis bond approaches the centre of the conjugated systems, ${ }^{30-32}$ rather strong 
absorbance in this region by the 15 or $15^{\prime}$-cis-isomers was expected. This absorbance is reflected in the $\mathrm{Q}$ values for these isomers, which are greater than those of the all-trans-, 13 or $13^{\prime}-$ cis-, and 9 or $9^{\prime}$-cis-isomers (table 1). The Q values of 15 or $15^{\prime}$ cis- and 13 or $13^{\prime}$-cis- $\beta$-carotene are typical as in reference. ${ }^{20}$ The 9 or $9^{\prime}$-cis-isomers $Q$ values are similar as reported in. ${ }^{6,33}$ No cis position was assigned to the other peaks (1, 2, 3, 9 and 12) because of inconsistent wavelength shift and no $Q$ ratio is available.

\subsection{Mechanism}

It is known that Lewis acids such as titanium tetrachloride and ferric chloride, can catalyse cis-trans isomerization of compounds containing double bonds through the formation of an intermediate radical carbocation. ${ }^{34}$ The radical carbocation is $s p^{3}$ hybridized and also an $s p^{2}$ double bond of polyenes converted into a single bond. Subsequently, free rotation about the new single bond would then form cis-isomers according to the following possible mechanism for the isomerization of $\beta$-carotene.

$$
\begin{aligned}
& (\beta \text {-carotene })_{\text {trans }}-e \leftrightarrow\left(\beta \text {-carotene }{ }^{\bullet+}\right)_{\text {trans }} \\
& \left(\beta \text {-carotene }{ }^{\bullet+}\right)_{\text {trans }} \leftrightarrow\left(\beta \text {-carotene }{ }^{\bullet+}\right)_{\text {cis }} \\
& \left(\beta \text {-carotene }{ }^{\bullet+}\right)_{\text {cis }}+e \leftrightarrow(\beta \text {-carotene })_{\text {cis }}
\end{aligned}
$$

This mechanism is supported by recent studies. ${ }^{34-36}$

\section{Conclusion}

The present research: (1) demonstrates that the catalytic activity of titanium tetrachloride towards the formation of geometrical isomers of $\beta$-carotene with high degree of shape selectivity by the polymeric C30 stationary phase; (2) unambiguously confirms the double bond configuration of $\beta$-carotene isomers in reverse phase liquid chromatography; and (3) supplements the existing spectroscopic data on $\beta$ carotene isomers.

\section{Acknowledgements}

The authors gratefully acknowledge financial supports from the National Science Council of Republic of China (R.O.C), Taiwan.

\section{References}

1. Moon R C 1989 J. Nutr. 119127

2. Cutler R G 1991 Am. J. Clin. Nutr. 53373

3. Fakourelis N, Lee E C and Min D B 1987 J. Food Sci. 52234

4. Gao G, Deng Y and Kispert L D 1998 J. Phys. Chem. $B 1023897$

5. Pesek C A and Warthesen J J 1990 J. Agric. Food Chem. 381313

6. Pesek C A, Warthesen J J and Taoukis P S $1990 \mathrm{~J}$. Agric. Food Chem. 3841

7. Wei C C, Gao G and Kispert L D 1997 J. Chem. Soc. Perkin Trans. 2783

8. Haugan J A, Englert G, Aakermann T E and Glinz S 1994 Acta Chem. Scand. 48769

9. Ding M R, Grant J L, Metzger R M and Kispert L D 1988 J. Phys. Chem. 924600

10. Konovalov V V and Kispert L D 1999 J. Chem. Soc. Perkin Trans. 2901

11. He Z, Gao G E, Kispert L D, Strand A and LiaaenJensen S 2002 J. Phys. Chem. A106 2520

12. Khachik F, Spangler C J and Smith J C 1997 Anal. Chem. 691873

13. Emenhiser C, Sander L C and Schwartz S J $1995 \mathrm{~J}$. Chromatogr. A707 205

14. Emenhiser C, Simunovic N, Sander L C and Schwartz S J 1996 J. Agric. Food Chem. 443887

15. Lin C H and Chen B H 2003 J. Chromatog. A1012 103

16. Bohm V, Nienaber $\mathrm{N}$ L $\mathrm{P}$, Ferruzzi $\mathrm{M} G$ and Schwartz S J 2002 J. Agric. Food Chem. 50221

17. Tsukida K, Saiki K, Takii T and Koyama Y $1982 J$. Chromatogr. 245359

18. Tai C Y and Chen B H 2000 J. Agric. Food Chem. 48 5962

19. Chen B H, Peng H Y and Chen H E 1995 J. Agric. Food Chem. $\mathbf{4 3} 1912$

20. Chen J P, Tai C Y and Chen B H 2004 J. Chromatogr. A1054 261

21. Dolan J W 1987 LC GC 51030

22. Schmitz H H, Emenhiser C and Schwartz S J $1995 J$. Agric. Food Chem. 431212

23. Vecchi M, Englert G, Maurer R and Meduna V 1981 Hel. Chim. Acta 642746

24. Koyamam Y, Hosomi M, Miyata A, Hashimoto H, Reames S A, Nagayama K, Kato-Jippo T and Shimamura T 1998 J. Chromatogr. A439 417

25. Hengartner U, Bernhard K, Meyer K, Englert G and Glinz E 1992 Helv. Chim. Acta 751848

26. Khachik F, Englert G, Daitch CE, Beecher G R, Tonucci L H and Lubsy W R 1992 J. Chromatogr. 582 153

27. Hashimoto H, Koyama Y T and Shimamura T $1988 \mathrm{~J}$. Chromatogr. 44882

28. Katayama N, Hashimoto H, Koyama Y and Shimamura T 1990 J. Chromatogr. 519221

29. Khachik F, Beecher G R, Goli M B, Lusby W R and Smith J C 1992 Anal. Chem. 642111

30. Zechmeister L 1994 Chem. Rev. 34267 
31. Zechmeister L 1962 Cis-trans isomeric carotenoids, vitamins and arylpolyenes (New York: Academic Press)

32. Emenhiser C, Englert G, Sander L C, Ludwing B and Schwartz S J 1986 J. Chromatogr. A719 333

33. Liu H L, Kao T H and Chen B H J. Chromatogra. (in press)
34. Gao Y, Kispert L D, Konovalova T A and Lawrence J N 2004 J. Phys. Chem. B108 9456

35. He Z, Gao Y, Hand E S, Kispert L D, Strand A and Jensen S L 2002 J. Phys. Chem. A106 2520

36. Gao Y and Kispert L D 2003 J. Phys. Chem. B107 5333 